\title{
TERRITÓRIO, REGIÃO E FRONTEIRA
}

\author{
Análise Geográfica Integrada \\ da Fronteira Brasil/Paraguai \\ Edson Belo Clemente de Souza \\ VANDERLÉIA GeMelli
}

R E S U M O O presente artigo busca interpretar a região de fronteira entre Brasil e Paraguai por meio de uma análise geográfica integrada, envolvendo território, regiāo e fronteira. Compreende-se essa fronteira como um espaço com características contrastantes que constituem uma realidade contígua, mas também reticular, que está tanto sob os efeitos de uma dinâmica local como também global. Trata-se de um território dotado de contradiçōes, com espaços que compartilham de alguns problemas e de algumas caracteristicas em comum ou completamente diversas. Como procedimento metodológico foram utilizados levantamento bibliográfico, trabalho de campo, dados estatísticos do Instituto Brasileiro de Geografia e Estatística (IBGE) e do Dirección General de Estadisticas, Encuestas y Censos (DGEEC), que permitiram, no conjunto, interpretar uma regiāo de territórios transfronteiriços.

P A L A V R A S - C H A V E Fronteira; Brasil/Paraguai; território; regiāo.

\section{INTRODUÇÃO}

Este artigo tem por objetivo analisar a região fronteiriça entre Brasil e Paraguai como um espaço com características contrastantes que constituem uma realidade contígua e reticular, o que demanda uma análise geográfica integrada, envolvendo o território, a região e a fronteira, enquanto conceitos indissociáveis.

Com o advento do que alguns autores chamam globalização, o espaço se torna cada vez mais fluido, constituindo-se no meio-técnico-científico-informacional (Santos, 1996; 2000), interligado por redes e por densas relações entre seus atores, sobrepondo ou conectando os territórios em um processo em constante movimento de territorializaçãodesterritorialização-reterritorialização, movimento conhecido pela sigla t-d-r (Haesbaert, 2006; 2004).

Não obstante, tal fluidez não ocorre de maneira contínua e uniforme por todo o espaço e, consequentemente, pelo território, uma vez que o espaço é dotado de diferenciações advindas das diversas apropriações que se fazem dele. Sob esse viés, como nos ensina Milton Santos, as relações entre os objetos e as ações existentes variam conforme o lugar em vista de suas diferentes condições históricas, apropriações do espaço e acessos disponíveis em relação ao meio-técnico-científico-informacional, entre outros fatores.

Com base nessa premissa é possível justificar as diferenças socioespaciais verificadas nos dois lados da região de fronteira entre Brasil e Paraguai. O processo histórico de formação desses dois países se deu em condiçóes diferenciadas, apesar da proximidade entre eles e de similaridades latino-americanas existentes, como a condição de subdesenvolvimento. 
Para uma efetiva compreensão dessa região de fronteira, é necessária uma análise geográfica integrada do território, da região e da fronteira, haja vista que, embora as realidades apresentem condições reticulares, elas são influenciadas também por componentes de espaços contíguos, como a proximidade do Lago de Itaipu.

Para o desenvolvimento deste trabalho foram utilizados os seguintes procedimentos metodológicos: levantamento bibliográfico de teóricos que contribuem para a elucidação dos objetivos e do objeto investigado; trabalho de campo com entrevistas a agentes relevantes da realidade fronteiriça como o vice-cônsul do Brasil no Paraguai e o vice-cônsul do Paraguai no Brasil, moradores brasileiros e paraguaios, policiais militares, motoristas de vans, moto-taxistas; fotografias que evidenciaram a paisagem da fronteira com representaçôes do uso do território; e dados estatísticos do Instituto Brasileiro de Geografia e Estatística (IBGE) e da Direción General de Estatísticas, Encuestas y Censos (DGEEC), que permitiram, no conjunto, interpretar uma região de territórios transfronteiriços.

O texto está alinhavado no seguinte sentido: além desta breve introdução, a discussão do território, da região e da fronteira busca dar base teórica para subsidiar o que vem a seguir, a saber: a caracterização da fronteira do Brasil com o Paraguai, inserindo o turismo como indutor do desenvolvimento regional, pois esta é uma das diversas manifestaçôes da dinâmica territorial. As considerações finais tratam de demonstrar alguns resultados alcançados na pesquisa, bem como encaminhar ações vistas como necessárias para que a fronteira entre Brasil e Paraguai seja mais integrada.

\section{TERRITÓRIO, REGIÃO E FRONTEIRA}

A globalização configura lugares, tornando-os cada vez mais heterogêneos, dotados de uma diferenciação espacial caracterizada pelo surgimento de múltiplos territórios (Haesbaert \& Porto Gonçalves, 2006), que, ao mesmo tempo em que se distinguem pelas suas diferenças identitárias, também se conectam e se sobrepõem no emaranhado complexo das redes que constituem o espaço geográfico atual. Segundo Moreira (1997), assim como ontem era a contiguidade que integrava em uma mesma regionalidade pessoas diferentes, hoje a acessibilidade à informação é o dado integrador dos homens na rede, estando ou não próximos.

Para Santos (1996), os lugares se expressam pelas horizontalidades e pelas verticalidades. As relaçôes de horizontalidades podem ser lidas nos serviços que a cidade presta em seu entorno e que exigem deslocamentos periódicos da população: saúde, educação, comércio especializado, serviços públicos e bancários, dentre outros. Já a verticalidade insere os espaços em graus e em formas variadas nesse contexto global, os quais se utilizam dos benefícios da informação, haja vista a capacidade que possuem de unir em redes os diferentes espaços.

Território e região, enquanto categorias de análise geográfica, são indissociáveis, não podendo ser analisadas separadamente, uma vez que possuem estreita relação devido ao fato de que o movimento do território, que implica t-d-r, está intimamente ligado ao movimento de construção, de desconstrução e de reconstrução de novas regiôes.

A região é assim uma realidade que se concretiza por meio da ação de atores sociais, evidenciada a partir do momento em que se definem similaridades e relaçôes internas comuns, capazes de delimitá-las: "A região é, portanto, uma dimensão real da vivência dos indivíduos e dos grupos, e é a partir dela que se cria uma base territorial comum para um dado quadro de referência de pertencimento e identidades" (Haesbaert, 2004). 
A partir do momento em que há a construção do espaço geográfico por determinada sociedade, se dá também a formação do território, que nada mais é do que a expressão da apropriação e das relações (abstratas) que ocorrem no espaço geográfico entre os indivíduos, envolvendo poder. O espaço é, portanto, anterior ao território, como preconiza Raffestin (1993).

Sob esse aspecto, Santos (1994, p.78) sublinha que o território "[...] significa objetos, açôes e a constituição de redes, podendo ser compreendido como sinônimo de espaço geográfico socialmente organizado [...]”.

Uma vez que o território se constitui na organização espaço-social, ele se transforma e se redefine constantemente, tendo em vista que a sociedade sempre está em movimento, o que também indica uma centralidade na relação espaço-tempo na constante redefinição do espaço e, consequentemente, do território.

Raffestin (1993) compreende o território como sendo constituído a partir da apropriação do espaço, ou seja, "[...] é o espaço transformado historicamente pelas sociedades” (Raffestin, 1993 apud Saquet, 2009, p.78). A diferenciação entre Milton Santos e Claude Raffestin na concepção de espaço e de território é que, para o primeiro, o espaço geográfico é o conceito principal, e, para o segundo, o território é a categoria principal de análise geográfica. Embora distintos, espaço e território não podem ser separados, pois um é condição para a existência do outro.

Cada território possui uma identidade que o caracteriza no espaço, o que implica ser essa sua territorialidade, podendo assim haver, em uma determinada porção do espaço geográfico, vários territórios sobrepostos, com suas respectivas territorialidades. "A territorialidade é compreendida como relacional e dinâmica, mudando no tempo e no espaço, conforme as características de cada sociedade" (Raffestin, 1978 apud Saquet, 2009, p.78).

Assim, o território pode ser interpretado como um espaço social, historicamente produzido e organizado, permeado por relações de poder, por redes e por identidades, que estão em constante transformação no tempo.

O arranjo espacial e suas transformações são diretamente influenciados pela ação de alguns agentes principais, como o capital e o Estado, os quais intervêm na organização da sociedade. Sob esse aspecto, Corrêa (1998, p.60-1) afirma:

A organização espacial é o resultado do trabalho humano acumulado ao longo do tempo. No capitalismo, este trabalho realiza-se sob o comando do capital, quer dizer, dos diferentes proprietários dos diversos tipos de capital. Também é realizado através da ação do Estado capitalista. Isto quer dizer que o capital e seu Estado são os agentes da organização do espaço. Daí falar-se em espaço do capital.

A região de fronteira brasileira foi estabelecida com o nome de Faixa de Fronteira em 1974, delimitada a $150 \mathrm{~km}$ a partir do limite internacional, respeitando o recorte municipal. A criação desse território foi feita sob a óptica da segurança nacional, sendo até hoje um espaço carente de políticas públicas consistentes que promovam o desenvolvimento econômico (Machado, 2005).

Pensar a fronteira como forma diferenciada de organização territorial daquela da lógica capitalista também é necessário, pois a fronteira constitui um recorte analítico e espacial de diversas realidades sociais, políticas, econômicas e culturais. Enquanto categoria de análise espacial, ela envolve a problemática da volatilidade do capital e das relaçôes de produção pelo território. Além disso, a fronteira é palco para conflitos transculturais e identitários. 
Em função do modo de produção e das representações simbólicas, ideológicas e culturais, esses elementos se transformam e se condicionam mutuamente, sempre de maneira singular. Singularidade, todavia, não significa ausência de diferenciações internas e conflitantes. Logo, é pertinente pensar a fronteira como forma diferenciada de organização territorial no bojo da ordem territorial capitalista.

A questão das relações bilaterais e multilaterais com o país vizinho - isto é, os temas transfronteiriços - também faz parte da pauta de uma política de ordenamento territorial no âmbito nacional, pois possui importantes repercussões nos fluxos e mesmo em regiões às vezes distantes das fronteiras.

Para Corrêa (2004), a existência da fronteira internacional está associada a diferenças entre os dois lados. Descrevendo tipologias de posição geográfica de cidades, o autor comenta as características de cidades de fronteiras:

Diferenças de padrão monetário, regime político, etnias, língua e religião levam a que, em certos pontos da fronteira, estabeleçam-se postos de controle daquilo que atravessa de um lado para o outro. Nesses postos estabelece-se um conjunto de atividades em torno das quais se desenvolve uma cidade. Ela pode agregar outras funçôes, mas a de posto fronteiriço tende a ser muito importante. Sua área de influência tende a ser ampla, incluindo pelo menos dois países. E de modo corrente, há uma outra cidade do outro lado da fronteira que, de certo modo, cumpre papel semelhante. Exemplos: Foz do Iguaçu (Brasil) e Ciudad del Este (Paraguai) (Corrêa, 2004, p.319).

É na lógica capitalista que se nega a fronteira, conforme Gonçalves (2004), o qual afirma que o capital quer fluir pelo mundo sem fronteiras. Segundo Smith (1988), o capital não somente produz o espaço em geral, mas também produz as reais escalas espaciais que dão ao desenvolvimento desigual sua coerência, pois aprimorou sua capacidade de ser transescalar em seu próprio benefício, isto é, o do ganho rápido e sem constrangimentos escalares. Conforme Vitte (2007), as escalas são produzidas e não dadas ontologicamente a priori, pois são conteúdos e relações fluidas, contestadas e perpetuamente transgredidas. Apesar de fluidas e interpostas entre si, a autora acrescenta que toda escala é central e decisiva, material e politicamente, para estruturar os processos dialéticos da acumulação.

De acordo com Gonçalves (2004), a fronteira deriva do front, expressão militar que designa aquele espaço onde a guerra está sendo travada exatamente pelo controle do espaço. Definida a vitória pelo controle do espaço, o front transforma-se em fronteira e o espaço, em território. A fronteira substantiva tende a esconder o front que a fez.

Não obstante a etimologia da palavra fronteira, não há território sem sujeitos, portanto, todo o território se faz por meio dos sujeitos sociais. É preciso identificar as territorialidades que subjazem aos territórios.

Martins (1997, p.150) nos ajuda a compreender a fronteira como:

[...] essencialmente o lugar da alteridade. É isso que faz dela um lugar singular. À primeira vista é o lugar de encontro dos que, por diferentes razōes, são diferentes entre si, como o índio de um lado e os civilizados do outro; como os grandes proprietários de terra, de um lado e os camponeses pobres, de outro. Mas o conflito faz com que a fronteira seja essencialmente, a um só tempo, um lugar de descoberta do outro e de desencontro.

Para José de Souza Martins, a fronteira é uma linha de separação, seja concreta ou abstrata, não necessariamente rígida, como bem observa Haesbaert (2004). Para esse 
autor, há duas "lógicas espaciais" de fronteira. Uma é a "lógica territorial tradicional" e a outra é a "lógica reticular". Ambas são distintas, porém articuladas.

A "lógica territorial tradicional" é o modelo de ordenamento territorial por excelência dos Estados nacionais modernos, expressa por áreas onde as relações sociais estão delimitadas e reguladas de forma a serem estabelecidos recortes espaciais contínuos e contíguos que servem como quadro de referência para a ação dos agentes sociais. A identidade territorial tende a legitimar ou a ser legitimada pelas fronteiras político-territoriais.

A outra lógica, "espacial", é o padrão reticular de organização do território que envolve outras relações. Conforme observa Souza (2009a), a lógica da vida dos povos em áreas transfronteiriças questiona aqueles pressupostos, no vai e vem de brasileiros e de paraguaios na fronteira de Foz do Iguaçu com a Ciudad del Leste, como também no entrelaçamento de brasileiros e paraguaios vistos em território brasileiro e paraguaio. Essa realidade é uma demonstração do cotidiano da fronteira, com aspectos contraditórios, complexos e de complementaridade, seja pelos fluxos de serviços, de informações e de mercadorias ou pelas relações das culturas que os unem e os desunem.

As comunidades de fronteira, especialmente o estudo de caso de brasileiros e paraguaios, sejam migrantes ou não, vivenciam a ambiguidade dessas duas lógicas territoriais: ao mesmo tempo em que se deparam com o controle rígido das barreiras fronteiriças internacionais, convivem com múltiplas redes de solidariedade, de trocas comerciais, culturais e até mesmo políticas, de caráter transfronteiriço.

Nesses espaços o local e o internacional se articulam, estabelecendo vínculos e dinâmicas próprias, construídas e reforçadas pelos povos fronteiriços. Neles estão presentes as identidades e as culturas nacionais de cada um dos países envolvidos, que constroem, reelaboram e constituem outra cultura e identidade diferenciada, capaz de criar um novo lugar, com aspectos regionais. São regiōes que não "respeitam" as barreiras existentes, já que há ação e interação dos agentes fronteiriços, estimulando dinâmicas fronteiriças informais.

\section{CARACTERIZAÇÃO DA REGIÃO DE FRONTEIRA ENTRE BRASIL E PARAGUAI}

A região em estudo se destaca no plano de relações internacionais. A exemplo das relaçôes econômicas, culturais e geopolíticas com o Mercosul, a mobilidade populacional constante para o Paraguai influencia, no cotidiano da fronteira, outras identidades socioculturais. São territorialidades ${ }^{1}$ expressas nos costumes, nos ritmos, nos ritos e nos valores desses povos.

A área analisada compreende os municípios brasileiros e distritos paraguaios limítrofes ao Lago de Itaipu, pertencentes às faixas de fronteira de ambos os países. Os municípios brasileiros lindeiros ao Lago de Itaipu, que fazem fronteira com o Paraguai, estão inseridos na Mesorregião Oeste Paranaense, de acordo com a divisão regional proposta pelo IBGE.

Ao longo do tempo, essa região passou por mudanças e por transformaçōes do espaço geográfico, as quais caracterizam o movimento da sociedade no processo de territorialização-desterritorialização-reterritorialização (t-d-r).

A construção da Hidrelétrica de Itaipu e, consequentemente, a formação do Lago em 1982 constituem um dos acontecimentos que ocasionaram significativas mudanças no arranjo espacial da região em estudo, visto que a formação do Lago propiciou uma nova
1 De acordo com Guiseppe Dematteis (apud Saquet, 2007), a territorialidade não é o resultado do comportamento humano sobre 0 território, mas o processo de construção de tais comportamentos, o conjunto das práticas e dos conhecimentos dos homens em relação à realidade material, a soma das relações estabelecidas por um sujeito com o território (a exterioridade) e com outros sujeitos (a alteridade). 
2 Guaíra, Terra Roxa, Mal. Cândido Rondon, Santa Helena, Matelândia, Medianeira, São Miguel do Iguaçu e Foz do Iguaçu.

3 Diamante do Oeste, Foz do Iguaçu, Entre Rios do Oeste, Guaíra, Itaipulândia, Marechal Cândido Rondon, Medianeira, Mercedes, Missal, Pato Bragado, Santa Helena, Santa Terezinha de Itaipu, São José das Palmeiras, São Miguel do Iguaçu e Terra Roxa. Todos esses municípios, que compõem a região Costa Oeste do $\mathrm{Pa}$ raná, estão localizados em uma linha de fronteira ou em uma faixa de fronteira, ou são cidades-gêmeas (Foz do Iguaçu com Ciudad del Este e Guaíra com Salto Del Guairá), de acordo com a classificação do Programa de Desenvolvimento da Faixa de Fronteira (PDFF). Disponível em: <http:/www.integracao.gov.br/programas/ programasregionais/faixa/ municipios. asp?area $=\mathrm{spr}$ fronteira>. Acesso em: 15 fev. 2010.

4 Segundo os Censos do IBGE de 1990, de 2000 e de 2010, a população de Foz do Iguaçu é de, respectivamente, 190.123 hab., de 258.543 hab. e de 256.081 (diminuiu nos últimos dez anos em 0,95\%). feição à região Oeste do Paraná (Souza, 2009a). Assim, as inundações proporcionadas pelo represamento culminaram em novos limites de extensões territoriais aos municípios impactados, bem como reconfiguraram a paisagem e as características dos municípios que tiveram parte de suas terras alagadas. No momento da formação do lago, em 1982, oito municípios $^{2}$ foram atingidos do lado brasileiro, e hoje, após alguns desmembramentos e emancipações distritais, a região é composta por quinze municípios. ${ }^{3}$

Nesse contexto, de acordo com o IBGE, entre 1970 e 1996, a mesorregião Oeste do Paraná passou por intenso processo de urbanização. Tal ocorrência se deve, principalmente, ao fato de essa região ser a última fronteira de ocupação do Paraná, aliado ao processo de expansão da modernização da agricultura e à atração de mão de obra para trabalhar na construção da Usina Hidrelétrica de Itaipu.

A construção da hidrelétrica causou fortes impactos em toda região extremo-oeste do Paraná. Em Foz do Iguaçu, por exemplo, um dos principais impactos foi o grande aumento, em um curto espaço de tempo, da população: saltou de 33.966 habitantes em

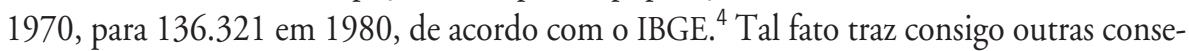
quências, como a necessidade de maior atendimento nos postos de saúde, mais moradias e toda a infraestrutura que necessitam, como saneamento básico, educação, lazer etc.

A partir de 1982 iniciou-se uma nova fase de desenvolvimento para a região dos municípios impactados pela construção da Hidrelétrica de Itaipu. Nesse período, formulou-se uma visão de região, uma vez que as mudanças proporcionadas pela hidrelétrica fizeram (e fazem) com que os municípios que se situam em torno do lago se encontrem inseridos em um mesmo contexto regional. Assim, por meio da relação entre tecnologia e sociedade, responsável pela transformação da realidade com a construção de um grande empreendimento, o espaço se reconfigurou e adquiriu um novo sentido.

Ocorre que a formação do Lago de Itaipu não modificou apenas a estrutura territorial, mas também as relações no território. De acordo com Souza (2009b, p.126), “[...] a formação do lago não mudou apenas o aspecto geográfico da região, alterou sua própria essência. A agricultura, base da economia regional, começou a ceder lugar à atividade turística [...]".

Esse novo empreendimento, portanto, culminou em grandes transformações sociais, econômicas e políticas, que constantemente se reorganizam. De acordo com Lima (2004, p.305):

[...] além do impacto favorável à economia capitalista, outros se sucederam, surpreendendo a população, especialmente a mais próxima das obras. Novos rumos foram tomados para a história regional, que foi reconstruída, mediante os desejos e necessidades emergentes da geração de energia para o provimento do progresso.

Esse novo cenário regional conferiu a possibilidade e a necessidade de novos projetos/programas e políticas para desenvolver a região de acordo com a nova realidade. Destacam-se, principalmente, as políticas voltadas para o desenvolvimento do turismo, haja vista a possibilidade de exploração dessa atividade pela criação, principalmente, de pequenas praias artificiais nas águas do Lago de Itaipu.

Segundo Souza (2009b, p.131): "Toda a infraestrutura turística começou a ser montada a partir de 1982[...]”, momento de formação do Lago da Hidrelétrica, uma vez que o apoio técnico e financeiro inicial para alavancar o turismo partiu da própria Itaipu. $\mathrm{O}$ autor considera ainda “[...] que a criação do Lago de Itaipu definiu uma nova 'paisagem', 
uma 'nova regionalização', que está sendo apropriada para alavancar a atividade turística" (Souza, 2009b, p.131).

A partir disso, a construção de Itaipu culminou em uma reterritorialização do espaço, ou seja, em uma mudança na estrutura social existente, fazendo com que a sociedade se adequasse ao impacto do alagamento, no sentido de superá-lo, bem como criasse novas formas de produção econômica, como a atividade turística. Sob esse viés, Lima (2004, p.307) sublinha: "A nova configuração espacial fora proporcionada não simplesmente pela inundação, mas por um novo agente modelador, o turismo".

Desse modo, a atividade turística constitui um elemento novo para essa região, que culmina em transformações na organização do espaço e abre caminhos para novas ações, caracterizadas pelas políticas públicas estatais.

Não obstante, notam-se diferenças entre Brasil e Paraguai na região de fronteira, pois, tratando-se de economia, o segundo apresenta o menor crescimento nos últimos vinte anos em relação aos países pertencentes ao Mercosul (Mercado Comum do Sul). Como explica Masi (2006, p.23), a economia paraguaia:

É a mais atrasada do Mercosul não por ser a menor, mas por ter se desenvolvido dentro de um modelo econômico com características adversas [...] caracterizou-se pela exportação de matérias-primas, pela triangulação comercial, com alta dose de informalidade e pela especulação financeira.

Nesse panorama econômico paraguaio, o Brasil desenvolve grande interferência devido à intensificação da relação comercial entre os dois países, principalmente a partir de 1970, período em que ocorreram muitas mudanças relacionadas à intensificação do processo de modernização da agricultura no Brasil e também no Paraguai. Vale ressaltar que a modernização da agricultura paraguaia foi alavancada pelo General Alfredo Stroessner, o qual pretendia, com esta modernização, a inserção do país no mercado externo; essa inserção coincide com o início da construção da Hidrelétrica de Itaipu.

É nesse período que inicia a migração de brasileiros para o Paraguai. Este fenômeno se deu em virtude da expulsão do campo brasileiro decorrente do processo de modernização e também pelo incentivo à ocupação da região leste paraguaia, até então esparsamente habitada. Para a modernização dessa região, eram necessárias pessoas que ocupassem a terra e nela trabalhassem. No intuito de seguir em seu projeto de modernização da agricultura, Stroessner iniciou um processo de incentivo à colonização da região por brasileiros, tarefa confiada a grandes colonizadoras. Forte propaganda foi feita no Brasil quanto às terras paraguaias, baratas e praticamente inabitadas, o que representava uma solução para aqueles que estavam sendo "expulsos" do campo brasileiro:

A mecanização da agricultura e a concentração fundiária na sociedade brasileira foram os principais fatores de "expulsão" de arrendatários, posseiros e pequenos agricultores brasileiros, enquanto que o preço baixo da terra e dos impostos e as facilidades de créditos agrícolas no Paraguai foram alguns dos mecanismos de atração (Albuquerque, 2008, p.3).

Mas mesmo com o incentivo à modernização, o Paraguai:

[...] caracterizou-se por ser um país mais comercial do que produtivo, com uma economia aberta (principalmente em razão do comércio ilegal ou contrabando) e, portanto, não pro- 
tecionista, com um escasso desenvolvimento industrial e agroindustrial, e especializado na exportação de duas ou três matérias-primas (soja, algodão e carne) (Masi, 2006, p.23).

A introdução do cultivo da soja no Paraguai se deve aos brasileiros que migraram para lá a partir da década de 1970. Mesmo se destacando no comércio, legal ou ilegal, a produção de soja no Paraguai tem sua expressividade: atualmente, ainda de acordo com Masi (2006), esse produto é responsável por 50\% das exportaçóes do país.

Um dos tipos de comercialização mais comuns verificado no Paraguai é o comércio de triangulação pela re-exportação. Ou seja, produtos são importados de países como Brasil e Argentina, que formam um triângulo com o Paraguai, e depois retornam a esses países pela re-exportação ou contrabando, livrando-se do pagamento de impostos. Ou, conforme Masi (2006, p.24), muitos produtos são “[...] provenientes, principalmente, dos Estados Unidos e dos países asiáticos em direção aos mercados altamente protegidos do Brasil e da Argentina, majoritariamente através de canais ilegais.". Ocorre, porém, que esse tipo de comércio de re-exportação não garantiu ao Paraguai um crescimento considerável de sua economia.

Em trabalhos de campo realizados em 17/4/2010 e 18/10/2010, no distrito de Marangatu, no Paraguai, pertencente ao departamento de Canindeyú, que faz fronteira com Pato Bragado, no Brasil, e em Salto del Guairá, também pertencente ao departamento de Canindeyú, em fronteira com Guaíra-PR, pode-se perceber uma série de aspectos que distinguem os respectivos países analisados.

Percebeu-se, do ponto de vista da infraestrutura básica (estradas pavimentadas, transporte, educação, saúde), do acesso a serviços e a produtos, dentre outros, que se trata de uma realidade oposta, "distante" da vivida no Brasil, pois se constitui em um espaço com grande carência de ações e de investimentos por parte do Estado.

$\mathrm{Na}$ localidade visitada durante trabalho de campo há o Puerto de Marangatu, do lado paraguaio, em precárias condições, responsável pela travessia somente de pessoas pelo Lago de Itaipu até o Porto de Pato Bragado do lado brasileiro. É por esse porto que muitos brasileiros residentes no Paraguai vêm até o Brasil para utilizar serviços (como saúde, assistência social e jurídica, aposentadoria, educação etc.).

Atualmente, existem 112 mil brasileiros (chamados de brasiguaios) residentes no

5 Conforme o depoimento do vice-cônsul do Brasil no Paraguai, em Salto del Guairá, Sr. José Lima.
Paraguai, segundo estatísticas oficiais. Já as estatísticas extraoficiais ${ }^{5}$ apontam para mais de 1 milhão de brasileiros, concentrados principalmente na porção leste paraguaia, região de fronteira com o Brasil, nos departamentos paraguaios de Alto Paraná, Canindeyú, Amambay, Itapua, Caaguazu e Caazapá.

No caso da fronteira entre Brasil e Paraguai, a oscilação cambial interfere diretamente nas relaçôes de compra e venda de mercadorias. Ciudad del Este (cidade que faz fronteira com Foz do Iguaçu-PR) e Salto del Guairá (localizada na fronteira com Guaíra-PR) são duas cidades de compristas brasileiros por mercadorias de preço baixo, em relação aos similares brasileiros.

A fronteira apresenta-se como espaço de complementaridade (na medida em que convivem em uma mesma realidade diferentes territorialidades) e, ao mesmo tempo, espaço de diferenciações (visto que há uma seletividade espacial que tende a favorecer grupos dominantes). Tal seletividade pode ser empregada tanto pelo capital, como pelo Estado, dotando determinados lugares com uma maior infraestrutura de acordo com as condições de organização socioespacial que apresentem e com o interesse do capital e do Estado.

$\mathrm{Na}$ fronteira Brasil/Paraguai entende-se que essa seletividade espacial se aplica aos diferentes tratamentos direcionados aos dois lados da fronteira quanto à implantação de políticas públicas por parte dos Estados paraguaio e brasileiro. 
A atuação do Estado é diferencial em ambos os lados da fronteira. No Paraguai, o sistema político-administrativo possui autonomia centralizada, enquanto que, no Brasil, essa autonomia é descentralizada em cada Estado da Federação. Desse modo, há, no Brasil, uma atuação maior do Estado pelo território que no Paraguai. Esse é um dos fatores que contribuem para a diferenciação ligada à infraestrutura turística existente na faixa de fronteira entre os dois países.

A atividade turística ${ }^{6}$ é o exemplo emblemático da compreensão desse estudo, pois, por possibilitar a integração dos povos e dinamicidade pela inerente prática social e econômica, a implantação de alguns programas turísticos brasileiros ${ }^{7}$ tem se reproduzido na fronteira paraguaia. A Itaipu Binacional representa um grande elo entre os dois países, haja vista suas atuações na região fronteiriça. ${ }^{8}$

No Brasil, além de o turismo receber maiores investimentos que no Paraguai, sua economia estatal favorece as potencialidades locais, em contraposição ao outro país, onde, em muitas cidades, a presença estatal é restrita, como é o caso da Ciudad del Este e de Marangatu. Por outro lado, observou-se que no Paraguai há uma grande atuação do capital na transformação do espaço geográfico, e o turismo de compras é bastante evidente na Ciudad del Este e em Salto del Guairá, por exemplo.

Nesse sentido, os atores que protagonizam as transformações do espaço geográfico são, principalmente, o Estado (instituições públicas), o capital (iniciativa privada) e a própria sociedade civil organizada.

De acordo com Corrêa (1998, p.48), "[...] o Estado, surgido dentro do modo de produção dominante, é o agente da regionalização". Assim, também a iniciativa privada e a sociedade civil organizada, muitas vezes agindo em conjunto com o Estado, ou na própria mobilização da sociedade, atuam no sentido de criar uma mesma realidade específica, contribuindo para a regionalização do espaço.

Todas essas transformações, inseridas no processo de globalização, criam múltiplos territórios, tornando o espaço geográfico complexo, que, longe de ser aniquilado pelo tempo, como defendem alguns estudiosos, ${ }^{9}$ torna-se cada vez mais heterogêneo e diferenciado, conectado, no entanto, pelo advento das redes. Torna-se imperativa, assim, a "multiterritorialidade", conforme Haesbaert (2004), em um complexo espaço global, ao mesmo tempo em ordem e em desordem com os territórios-redes.

Nesse contexto, assim como os territórios e as regiões, também as fronteiras estão longe de se dissolverem nesse emaranhado complexo de relaçóes que caracteriza o mundo globalizado. O que ocorre é uma afirmação ainda maior dessas categorias de análise geográfica, tornadas ainda mais complexas e que vêm caracterizar a multiplicidade de tempos-espaços concretizados e em constante movimento pelo processo de $\mathrm{t}-\mathrm{d}$-r. Haesbert (2004, p.178) enfatiza:

Sintetizando, a chamada desterritorialização, ou melhor, des-reterritorialização, e, consequentemente, os atuais processos de regionalização, estão fortemente vinculados ao fenômeno da compressão tempo-espaço - não no sentido de uma "superação do espaço pelo tempo" ou de um "fim das distâncias", mas de um emaranhado complexo de "geometrias de poder" de um espaço social profundamente desigual e diferenciado.

Dentro dessa dinâmica atual, também as fronteiras por vezes mudam de sentido, passando a significar muito mais do que simples limites político-organizacionais dos territórios institucionais. Em consonância com o Brasil, por meio do Ministério da
6 Estudos sobre turismo e fronteira estão se efetivando nos seminários internacionais de turismo de fronteiras, sendo que no ano de 2010 foi realizado o VII Seminário Internacional de Turismo de Fronteiras - Frontur 2010, em Assunção-Paraguai, cujo tema foi "La integración se hace más concreta".

7 No sentido de atender ao desenvolvimento da atividade e procurar dar-lhe um caráter mais relevante na agenda de governo, foram formuladas políticas, planos e programas que atualmente estão sob a coordenação do Ministério do Turismo MTur. A ação de maior expressividade do MTur no que diz respeito ao planejamento e à organização do território nacional para o turismo é o Programa de Regionalização do Turismo - Roteiro do Brasil.

8 Alguns dos projetos programas da Itaipu implantados no Brasil e com perspectivas de implantação no Paraguai: Cultivando Água Boa, Desenvolvimento Rura Sustentável, Plantas Medicinais, Coleta Solidária, Jovem Jardineiro, Produção de Peixes em Nossas Águas etc.

9 Segundo Virilio (1994 apud Araújo, 1998): "[...] este tempo único, universal, astronômico, se transformou no tempo do mundo rápido. Existe assim uma desqualificação do tempo local, mas também do espaço local, em proveito do tempo mundia e de um não-lugar [...] que diz respeito ao fim do hic et nunc (grifo do autor) ao fim do aqui e agora. (p. 130-1)". Para Virilio (1994), a corrida da sociedade é sempre em proveito da redução das distâncias, onde os espaços são eliminados. 
Integração (2005), as novas condições técnico-tecnológicas, como o sistema global de telecomunicações, tornam imperativas as mudanças no tratamento da fronteira. Muitas fronteiras da atualidade se constituem em espaços onde há uma mescla entre os dois lados, com interação constante pelo contínuo movimento dos fixos e dos fluxos, como é o caso da fronteira entre Brasil e Paraguai. São costumes, identidades, cotidianos próprios da fronteira e realidades que não veem a fronteira como uma linha rígida, intransponível, mas, sim, como uma região onde o lado de lá e o lado de cá se mesclam, se interpõem e convivem em uma só realidade. Não obstante, existe um quadro de diferenças sociais, políticas, infraestruturais e culturais, entre outras, que forma uma realidade complexa.

Vários fatores corroboram o panorama apresentado, como o fluxo contínuo de pessoas, de informaçôes, de mercadorias, de ideias etc., para que a fronteira represente, principalmente para quem nela vive, uma realidade única, a qual pode ser percebida/ constatada na fronteira entre Brasil e Paraguai.

Desse modo, a partir do momento em que há um espaço construído e, consequentemente, uma sociedade nele instalada, dá-se a formação do território. Este último é a expressão da organização que há em uma determinada porção do espaço, pelas relações que existem de dominação, de controle e de poder. Dessa perspectiva, o território é o

[...] produto de processos de controle, dominação e/ou apropriaçãao do espaço físico por agentes estatais e não estatais. Os processos de controle (jurídico/político/administrativo), dominação (econômico-social) e apropriação (cultural-simbólica) do espaço geográfico nem sempre são coincidentes em seus limites e propósitos. (Brasil - Ministério da Integração, 2005, p.21).

Sob essa lógica, a territorialização pode ser resultante tanto das ações do Estado por meio de políticas públicas, como também pelas empresas e ou pelas práticas das comunidades, através das identidades e das significações do espaço vivido.

Nesse sentido, as territorialidades nem sempre coincidem com os limites de um território formalmente instituído, como é o caso da fronteira entre Brasil e Paraguai. Na região de fronteira desses países existem territorialidades que ultrapassam seus limites territoriais e institucionais como a territorialidade dos brasiguaios, do narcotráfico, dos indígenas, do capital, entre outros. Sobretudo, "[...] o território é compreendido como um espaço de organização e luta, de vivência da cidadania e do caráter participativo da gestão do diferente e do desigual" (Saquet, 2007, p.91).

A fronteira entre Brasil e Paraguai constitui-se, portanto, em um espaço que possui a sobreposição de diversos territórios que apresentam semelhanças, mas também diferenças oriundas da seletividade espacial e econômica, pois, conforme Dias (2007, p.3):

A localização geográfica torna-se [...] portadora de um valor estratégico ainda mais seletivo. As vantagens locacionais são fortalecidas e os lugares passam a ser cada vez mais diferenciados pelo seu conteúdo - recursos naturais, mão de obra, infraestrutura de transportes, energia ou telecomunicaçôes, etc.

Dias se reporta a uma diferença de atratividade dos lugares para o capital, de acordo com a incorporação da técnica e da informação que apresentam. Assim, essa incorporação é desigualmente distribuída pelo território: aqueles que apresentam uma incorporação maior são mais atrativos ao capital. Dias (2007), assim como Haesbaert (2004), discorda 
de Virilio (1994 apud Araújo, 1998) em relação à aniquilação do espaço, uma vez que a instantaneidade, a rapidez da informação e a incorporação de novas técnicas se distribuem desigualmente pelo espaço, dotando-o de um valor estratégico diferencial e seletivo. Para a autora, "[...] associar contração de distâncias à negação do espaço situa-se no plano da utopia [...]" (Dias, 2007, p.3).

Por meio da análise da região de fronteira entre Brasil e Paraguai percebe-se que a seletividade dos lugares é o diferencial dos dois lados da fronteira. $\mathrm{Na}$ faixa de fronteira brasileira, o Estado atua enquanto criador de políticas públicas ligadas ao turismo, que contribuem para uma singularidade regional, caracterizando também uma seletividade espacial, o que não ocorre no Paraguai.

Nesse contexto, a regionalização enquanto processo de classificação de regiôes, institucionais ou não, é forjada também, de acordo com Brasil - Ministério da Integração (2005, p.20-1):

[...] na própria ação dos indivíduos e comunidades que, conjugando múltiplos interesses, econômicos e políticos, e produzindo identificações sócio-culturais diversificadas, redesenham constantemente seus espaços.

Outro elemento de diferenciação entre os dois países que deve ser destacado é a infraestrutura para o turismo existente no Brasil e no Paraguai. O primeiro possui uma estrutura forte e mais consolidada se comparada à do Paraguai, que, praticamente, não possui ou é muito incipiente. Isso, em parte, pode ser explicado pelo seguinte fator: no que diz respeito à Itaipu, os recursos liberados para Brasil e Paraguai são igualmente divididos, porém os direcionamentos dados a esses recursos são diferentes. O Paraguai, por exemplo, direciona os recursos recebidos para investimentos em obras sociais, ou em ajuda aos distritos, enquanto que muitos dos investimentos no Brasil são dirigidos para o turismo. Assim, também, o governo central paraguaio não oferece autonomia aos departamentos, atuando apenas nas áreas consideradas prioritárias, tendo por base as condições e os problemas sociais do país; o turismo não constitui uma delas.

Embora incipientes, os investimentos ligados ao turismo no Paraguai não são, no entanto, inexistentes. Exemplo disso é a recente criação da Polícia de Turismo, em 2009, que atua em Ciudad del Este e em Salto del Guairá, cidades que se destacam no turismo de compras. A Polícia está ligada à Comandancia de la Policía Nacional e atua no sentido de orientar e de defender os turistas. Para tanto, são promovidas medidas de proteção, de apoio e de assistência aos turistas que visitam essas cidades e, de acordo com esse órgão: "La División de Seguridad Turística contribuye al mejoramiento de la calidad de la información, protección y seguridad en la entrada al país, en las rutas, caminos y centros de concentración de turistas" ${ }^{10}$ A criação da Polícia de Turismo destaca a vocação turística paraguaia, ligada ao turismo de compras provindo do Brasil.

Por outro lado, do ponto de vista do processo de urbanização, de acordo com dados do IBGE, no Brasil, e da DGEEC, no Paraguai, pode-se constatar que do lado brasileiro da faixa de fronteira o grau de urbanização é maior, e na fronteira paraguaia, na maioria dos distritos possui população rural superior à urbana. As Tabelas 1 e 2 caracterizam cada um dos municípios e distritos da regiấo, do Brasil e do Paraguai, com dados referentes à área territorial, ao número de habitantes e ao total de população rural e urbana:
10 "A Divisão de Segurança Turística contribui 0 melhoramento da qualidade da informação, proteção e segurança na entrada ao país, nas estradas, caminhos e centros de concentração de turistas". Disponível em: $<w w w$. seguridadurbanayturistica.gov.py>. Acesso em $06 \mathrm{dez} .2011$ 
Tabela 1 - População e área territorial dos municípios lindeiros ao Lago de Itaipu no Brasil -2010

\begin{tabular}{|l|r|r|r|r|}
\hline Município & $\begin{array}{c}\text { No de } \\
\text { habitantes } \\
\text { (Censo 2010) }\end{array}$ & $\begin{array}{c}\text { População } \\
\text { urbana } \\
\text { (Censo 2010) }\end{array}$ & $\begin{array}{c}\text { População } \\
\text { rural } \\
\text { Censo 2010) }\end{array}$ & $\begin{array}{c}\text { Área territorial } \\
\left(\mathrm{km}^{2}\right)\end{array}$ \\
\hline Foz do Iguaçu & 256.081 & 253.950 & 2.131 & 610,209 \\
\hline Santa Terezinha de Itaipu & 20.834 & 18.832 & 2.002 & 267,49 \\
\hline São Miguel do Iguaçu & 25.755 & 16.476 & 9.279 & 848,67 \\
\hline Itaipulândia & 9.027 & 4.742 & 4.285 & 332,32 \\
\hline Medianeira & 41.830 & 37.403 & 4.427 & 325,17 \\
\hline Missal & 10.474 & 5.420 & 5.054 & 232,04 \\
\hline Santa Helena & 23.425 & 12.596 & 10.829 & 759,12 \\
\hline Diamante D’Oeste & 5.027 & 2.561 & 2.466 & 309,147 \\
\hline São José das Palmeiras & 3.831 & 2.412 & 1.419 & 183,28 \\
\hline Mal. Cândido Rondon & 46.799 & 39.134 & 7.665 & 748,28 \\
\hline Mercedes & 5.046 & 2.439 & 2.607 & 199,08 \\
\hline Pato Bragado & 4.823 & 2.991 & 1.832 & 539,03 \\
\hline Entre Rios do Oeste & 3.922 & 2.641 & 1.281 & 120,33 \\
\hline Terra Roxa & 16.763 & 12.802 & 3.961 & 803,48 \\
\hline Guaíra & 30.669 & 28.176 & 2.493 & 568,845 \\
\hline Total & 508.110 & 445.011 & 63.099 & $6.937,491$ \\
\hline
\end{tabular}

Fonte: IBGE, <www.ibge.gov.br>.

Quanto aos municípios lindeiros ao Lago de Itaipu, pertencentes à faixa de fronteira brasileira, pode-se constatar, de acordo com a Tabela 1, que se trata de municípios com grande parte da população vivendo na zona urbana. Os municípios de Foz do Iguaçu, Santa Terezinha de Itaipu, Medianeira, Marechal Cândido Rondon, Terra Roxa e Guaíra são os que apresentam maior diferença entre população urbana e rural. $\mathrm{O}$ único muni-

11 Estudo mais detalhado sobre a urbanização da região Costa Oeste do Paraná pode ser visto em Graff (2010). cípio com população rural superior à urbana é Mercedes, mas a diferença é pequena. ${ }^{11}$

Segundo Limonad (2008), para entender a urbanização brasileira hoje é necessário perceber as diferenças e as diversidades das transformaçōes. A urbanização está ligada à estruturação do território, compreendendo a reprodução dos meios de produção, a reprodução da força de trabalho e da família, e, por conseguinte, a distribuição espacial da população e das atividades produtivas.

$\mathrm{Na}$ Tabela 2, referente aos distritos do Paraguai, percebe-se que os dados da população são relativamente diferentes dos do Brasil: 
Tabela 2 - População e área territorial dos distritos lindeiros ao Lago de Itaipu no Paraguai

\begin{tabular}{|l|r|r|r|r|}
\hline Distrito & $\begin{array}{c}\text { No de } \\
\text { habitantes } \\
\text { (Censo 2002) }\end{array}$ & $\begin{array}{c}\text { População } \\
\text { urbana } \\
\text { (Censo 2002) }\end{array}$ & $\begin{array}{c}\text { População } \\
\text { rural } \\
\text { Censo 2002) }\end{array}$ & $\begin{array}{c}\text { Área territorial } \\
\left(\mathrm{km}^{2}\right)\end{array}$ \\
\hline Salto del Guairá & 11.298 & 6.653 & 4.645 & 1382,48 \\
\hline La Paloma & 6.373 & 3.929 & 2.444 & 728,76 \\
\hline Gral. Francisco C. Alvarez & 8.884 & 2.692 & 6.192 & 1043,91 \\
\hline Nueva Esperanza & 9.951 & 3.018 & 6.933 & 1342,44 \\
\hline San Alberto & 11.523 & 4.221 & 7.302 & 1046,8 \\
\hline Minga Porá & 11.180 & 1.393 & 9.787 & 881,25 \\
\hline Mbaracayú & 8.337 & 449 & 7.888 & 1174,43 \\
\hline Hernandárias & 63.248 & 47.266 & 15.982 & 1519,27 \\
\hline Total & 130.794 & 69.621 & 61.173 & $9.119,34$ \\
\hline
\end{tabular}

Fonte: DGEEC, Censo Nacional de Población y Vivienda, 2002.

De acordo com a Tabela 2, ocorre o oposto em relação ao lado brasileiro, uma vez que, no Paraguai, os distritos apresentam menor grau de urbanização. Dos oito distritos, apenas três (Salto del Guairá, La Paloma e Hernandárias) possuem maior contingente de população vivendo na zona urbana. Os demais (Gral. Francisco Caballero Alvarez, Nueva Esperanza, San Alberto, Minga Porá e Mbaracayú) possuem maior população rural. Além disso, em alguns desses distritos, a diferença entre população rural e população urbana é bastante representativa, como é o caso do distrito de Minga Porá, onde a população urbana soma 1.393 habitantes e a rural 9.787 habitantes.

A urbanização representa a estruturação do território que é condicionada pelos aspectos sociais, econômicos e políticos de determinados momentos da sociedade, que se diferenciam de acordo com as possibilidades e as características de cada lugar: "O urbano é o modo como a reprodução do espaço se realiza na contemporaneidade, como realidade e possibilidade" (Carlos, 2008, p.183). Essa autora geógrafa e muitos outros, inclusive não geógrafos, ${ }^{12}$ balizam suas análises na relação espaço-tempo, contextualizando as características de cada período e em determinado lugar com as singularidades que o identificam.

Assim, compreende-se que a distribuição da população e a análise das bases produtivas são instrumentos valiosos para entender o fenômeno urbano nas diferentes regiōes e em diferentes esferas, capaz de traduzir informaçōes importantes sobre a organização social, cultural e política, demonstrando aspectos peculiares de cada região e o grau de envolvimento na expansão do sistema capitalista.

Essa caracterização permite ter uma visão geral da região de fronteira entre Brasil e Paraguai e constatar que, ao mesmo tempo em que a fronteira possui situações e preocupaçôes em comum, ligadas à segurança, à saúde, à educação e demais serviços, as condiçóes de cada lado são diferentes, visto que no Brasil a qualidade e a quantidade dos serviços ofertados são em maior proporção que no país vizinho. Esse é um fato que explica a grande quantidade de pessoas (brasileiros ou paraguaios) que vivem na faixa de fronteira paraguaia e procuram o atendimento no Brasil. Essa é uma das características marcantes da fronteira, pois se reflete no fluxo constante de pessoas, de mercadorias e de serviços.
12 Bergmann (1986); Lefebre (1991); Castells (1983); Gottdiener (1993) e outros. 


\section{CONSIDERAÇÕES FINAIS}

13 Gemelli \& Souza (2010); Guimarães (2010).

\begin{abstract}
Edson Belo Clemente de Souza é geógrafo; Professor Associado da Unioeste; membro do Grupo de Estudos Fronteiriços (GEF) e coordenador do Laboratório de Estudos Regionais (LA$B E R)$; pesquisador do CNPq e Fundação Araucária. Email: ebelo2003@yahoo.com.br.
\end{abstract}

Vanderléia Gemelli é mestranda em Geografia (Unioeste/Campus de Francisco Beltrão); pesquisadora do GEF e do LABER. Email: leia gemelli@yahoo.com.br

Artigo recebido em julho de 2011 e aprovado para publicação em setembro de 2011.
A fronteira entre Brasil e Paraguai constitui-se em local privilegiado para o estudo do território e da região, pois se concretiza em campos de força, de conflitos, de solidariedade e de contradiçỗes onde se dá a sobreposição de vários territórios, ${ }^{13}$ destacando-se determinadas características peculiares que diferenciam esse espaço dos demais.

A organização da estrutura socioespacial entre os dois lados da fronteira Brasil/Paraguai abriga espaços contíguos, mas as populaçóes vivem em realidades distintas, oriundas de um processo histórico diferencial de ambas as sociedades. Apesar da contiguidade, o território, a região e a fronteira estão permeados por realidades contrastantes.

As informações obtidas demonstram diferentes dinâmicas socioespaciais entre esses lugares da fronteira. Os municípios do lado brasileiro, considerados de forte projeção agrícola, tiveram alteração em sua base econômica com a construção da Hidroelétrica de Itaipu, quando perderam parte de suas terras produtivas, fator principal que resultou na reestruturação de seu território e mudanças na paisagem.

A Itaipu é um "divisor de águas" na história do desenvolvimento urbano desses municípios, pois promoveu significativas alterações sob o ponto de vista urbano e econômico, implicando em transformações espaciais, configurando na região uma nova realidade e um novo cenário pelo incentivo da atividade turística como forma de produção desse espaço.

Para uma efetiva compreensão desse espaço fronteiriço, é necessário que a análise seja integrada, permitindo compreender a complexidade espacial de lógicas contíguas e reticulares. Assim, a interpretação dessa região de fronteira perpassa pela análise integrada de questôes referentes ao território, à região e à fronteira, na medida em que esses fatores fazem parte do cotidiano desse lugar, estando sobrepostos em um emaranhado de relaçóes complexas, característico do mundo globalizado atual.

A localização dos municípios dessa região pressupõe uma lógica de relações econômicas, políticas, sociais e culturais, articulando-os através de um sistema de objetos e de açôes. O estudo dessa região revela alguns eixos transversais representados pela viabilidade de algumas reflexões que constituem a região de fronteira.

\section{REFERÊNCIAS BIBLIOGRÁFICAS}

ALBUQUERQUE, J. L. C. "Imigração em territórios fronteiriços". Anais do VI Congresso Português de Sociologia - mundos sociais: saberes e práticas. Universidade Nova de Lisboa, 2008.

ARAÚJO, H. R. Tecnociência e cultura: ensaios sobre o tempo presente. São Paulo: Estação Liberdade, 1998.

BERMAN, M. Tudo que é sólido desmancha no ar. A aventura da modernidade. São Paulo: Companhia das Letras, 1986.

BRASIL. Ministério da Integração Nacional. Secretaria de Programas Regionais. Proposta de Reestruturação do Programa de Desenvolvimento da Faixa de Fronteira. Brasília: Ministério da Integração Nacional, 2005.

CARLOS, A. F. "Urbanização da sociedade: um desafio à reflexão". Revista Cidades, v. 5, no 8, p.183-6, 2008.

CASTELLS, M. A questão urbana. São Paulo: Paz e Terra, 1983. 
CORRÊA, R. L. "Posição geográfica de cidades". Revista Cidades. V. 1, n. 2, p. 317-323, 2004.

. Região e organização espacial. 6. ed. São Paulo: Ática, 1998.

DIAS, L. C. "Redes de informação, grandes organizações e ritmos de modernização". ETC, espaço, tempo e crítica: Revista Eletrônica de Ciências Humanas e Sociais. n. 2, v. 1, jul. 2007.

GEMELLI, V.; SOUZA, E. B. C. "As territorialidades existentes no espaço fronteiriço de Brasil e Paraguai: Brasiguaios, indígenas, atividade turística e vilas de trabalhadores de Itaipu". Anais do XVI Encontro Nacional de Geógrafos: Crise, práxis e autonomia: espaços de resistências e de esperanças. Porto Alegre, 2010.

GONÇALVES, C. W. P. "Processos planetários e fronteiras móveis". In: BRANDÃO, M. A. (Org.) Milton Santos e o Brasil. Rio de Janeiro: Editora Fundação Perseu Abramo, 2004.

GOTTDIENER, M. A produção social do espaço urbano. São Paulo: Edusp, 1993.

GRAFF, V. D. A urbanização dos municípios da regiāo Costa Oeste do Paraná: processos de formação. Mal. Cândido Rondon, PR: Unioeste, 2010 (TCC em Geografia).

GUIMARÃES, G. S. A territorialidade dos moto-taxistas na Ponte Internacional da Amizade entre Brasil e Paraguai. Mal. Cândido Rondon, PR: Unioeste, 2010 (TCC em Geografia). HAESBAERT, R.; GONÇALVES, C. W. P. A nova des-ordem mundial. São Paulo: Editora Unesp, 2006.

. "Desterritorialização, multiterritorialidade e regionalização". In: LIMONAD, E.; HAESBAERT, R.; MOREIRA, R. (Orgs.) Brasil século XXI por uma nova regionalização - agentes, processos e escalas. São Paulo: Max Limonad, 2004.

- O mito da desterritorialização: do "fim dos territórios" à multiterritorialidade. Rio de Janeiro: Bertrand Brasil, 2004.

LEFEBVRE, H. The production of space. Oxford: Blackwell Publishing, 1991.

LIMA, I. T. C. Itaipu: as faces de um mega projeto de desenvolvimento (1930-1984). Niterói: Germânica, 2004.

LIMONAD, E. "Espaço-tempo e urbanização: algumas considerações sobre a urbanização brasileira". Revista Cidades, v. 5, n. 8, p.243-61, 2008.

MACHADO, L. O. et al. Bases de uma politica integrada de desenvolvimento regional para a Faixa de Fronteira. v. 1, 1. ed. Brasília, DF: Ministério da Integração Nacional, 2005. $450 \mathrm{p}$.

MARTINS, J. S. Fronteira: a degradação do outro nos confins do humano. São Paulo: Hucitec, 1997.

MOREIRA, R. Da região à rede e ao lugar: a nova realidade e o novo olhar geográfico sobre o mundo. Revista Ciência Geográfica, n. 6, p.1-11, 1997.

MASI, F. "Paraguai - Brasil e o projeto Mercosul". Revista Política Externa. São Paulo: Editora Paz e Terra, v. 14, n. 3, dez/jan/fev - 2005/2006.

SANTOS, M. A natureza do espaço: técnica e tempo, razão e emoção. São Paulo: Hucitec, 1996.

. "O retorno do território". In: SANTOS, M. et al (Orgs.). Território: globalização e fragmentação. São Paulo: Hucitec/Anpur, 1994. p.15-20.

. Por uma outra globalização: do pensamento único a consciência universal.

Rio de Janeiro: Record, 2000.

SAQUET, M. A. Abordagens e concepçōes do território. São Paulo: Expressão Popular, 2007. 
SAQUET, M. A.; SPOSITO, E. S. Território e territorialidades: teorias, processos e conflitos. São Paulo: Expressão Popular, 2009.

SMITH, N. Desenvolvimento desigual. Rio de Janeiro: Bertrand Brasil, 1988.

SOUZA, E. B. C. A (re)produção da regiāo do Lago de Itaipu. Cascavel: Edunioeste, 2009a. - "Tríplice fronteira: fluxos da região Oeste do Paraná com o Paraguai e Argentina”. Revista Terra Plural, v.1, n. 1, 2009 b.

RAFFESTIN, C. Por uma geografia do poder. São Paulo: Ática, 1993.

VITTE, C. C. S.; SENHORAS, E. M. "A construção escalar do regionalismo transnacional”. Encontro da Associação Nacional de Pós-Graduação e Pesquisa em Planejamento Urbano e Regional. Belém, PA, 21 a 25 de maio de 2007.

A B S T R A C T This article seeks to examine the border between Brazil and Paraguay through an integrated geographical analysis, which involves territory, region and border. This border is understood as an area with contrasting characteristics that constitute a contiguous but also a reticulated reality, which is under the effects of both local and global dynamics. It is a territory endowed with contradictions, with areas that share some problems and characteristics that are similar or completely diverse. Literature review, fieldwork, statistical data from Instituto Brasileiro de Geografia e Estatistica - IBGE (Brazilian Institute of Geography and Statistics) and from Dirección General de Estadísticas, Encuestas y Censos - DGEEC (General Directorate of Statistics, Surveys and Censuses of Paraguay) were used as methodology. These procedures allowed to interpret a region of cross-border territories.

K E Y W O R D S Border; Brazil/Paraguay; territory; region. 